\title{
Classification of Vitamin K-deficient Mutants of Staphylococcus aureus
}

\author{
By A. SĂSĂAMAN AND MARIETTA SURDEANU \\ Laboratory of Bacterial Genetics, Dr I. Cantacuzino Institute, \\ Bucharest 35, Romania \\ AND V. PORTELANCE \\ Institut de Microbiologie et d'Hygiène de l'Université de Montréal, \\ Laval, Quebec, Canada \\ AND R. DOBARDZIC AND S. SONEA \\ Department of Microbiology and Immunology, Université de Montréal, \\ Montreal, Quebec, Canada \\ (Accepted for publication ro November 1970) \\ SUMMARY \\ Twelve menaquinone-lacking mutants of Staphylococcus aureus, selected \\ by neomycin, could be classified according to the point of their metabolic \\ block. The mutants of class I were affected prior to the synthesis of \\ shikimic acid, those of class II at a point following the synthesis of shikimic \\ acid, and class III after the separation of the paths of aromatic amino acid \\ biosynthesis but prior to the formation of the naphthoquinone ring. Mutants \\ of class IV were probably affected at the level of synthesis of the isoprenoid \\ side chain of menaquinone.
}

\section{INTRODUCTION}

The vitamin K-deficient mutants of Staphylococcus aureus, recently isolated by means of neomycin (Săsărman et al. I968; Săsărman et al. 1969), afford an ideal means for studying menaquinone biosynthesis, since staphylococci, like the other Grampositive cocci, possess only one type of quinone (Bishop, Pandya \& King, I962; Jeffries et al. 1967). The early stages of menaquinone biosynthesis are common to the biosynthesis of the aromatic amino acids (Cox \& Gibson, 1964, 1966) up to the point of formation of chorismate or prephenate. Thereafter, the path diverges and the steps in the formation of the naphthoquinone ring are poorly understood (Gibson \& Pittard, 1968; Zenk \& Leistner, 1968). For identification of the unknown steps in menaquinone synthesis, only the mutants affected at some specific stages of the synthesis of the naphthoquinone nucleus are important. Our study was undertaken in order to identify such mutants among catalase-positive dwarf colony mutants of $S$. aureus and to try to classify the vitamin K-deficient mutants of $S$. aureus in several groups according to the point of their metabolic block. 


\section{METHODS}

Strains. The menaquinone-negative ( $\left.\mathrm{meq}^{-}\right)$mutants investigated were derived from the following normal Staphylococcus aureus strains maintained in the collection of the Dr I. Cantacuzino Institute, Bucharest: $S$. aureus 3c, II s, NINA, 1363. All these strains were isolated from hospital patients in Bucharest.

Isolation and characters of the meq- mutants of Staphylococcus aureus

(a) Selection of mutants. The meq- mutants of Staphylococcus aureus were obtained by selection with neomycin, as previously described (Sǎsărman et al. 1968). On nutrient agar plates containing neomycin these mutants appeared as dwarf colonies similar to haemin-deficient mutants. Differentiation from the latter was carried out on the basis of catalase production.

(b) Catalase production. This was tested by placing a drop of $\mathrm{H}_{2} \mathrm{O}_{2}(3 \%, \mathrm{v} / \mathrm{v})$ on the surface of a $48 \mathrm{~h}$. culture of the appropriate mutant growing on agar. The rapid appearance of gas bubbles indicated the presence of catalase activity in the mutant.

(c) Stimulation by menadione. To test the influence of menadione on growth and on vitamin $\mathrm{K}_{2}$ synthesis, the mutants were grown on nutrient agar or on a synthetic medium supplemented with I $\mu \mathrm{g}$. menadione $/ \mathrm{ml}$. The cultures were incubated at $37^{\circ}$ for $48 \mathrm{~h}$., together with controls grown in the absence of menadione.

(d) Stimulation by shikimic acid. To test the influence of this substance on growth and on vitamin $\mathrm{K} 2$ synthesis, the mutants were grown on nutrient agar supplemented with $300 \mu \mathrm{g}$. shikimic acid $/ \mathrm{ml}$. The cultures were incubated at $37^{\circ}$ for $48 \mathrm{~h}$., together with a control cultured in the absence of shikimic acid.

(e) Nutritional requirements of the mutants. To compare the nutritional requirements of the mutant and parental strains, the synthetic medium described by Weaver $\&$ Pattee (1964) was supplemented with $5 \mu \mathrm{g}$. $p$-aminobenzoic acid $+\mathrm{I} \mu \mathrm{g}$. menadione/ $\mathrm{ml}$. On this medium (complete synthetic, or $\mathrm{C}$ medium) all the menadione-stimulated mutants grew normally with the exception of mutant SHSL I, a derivative of Staphylococcus aureus strain $3 \mathrm{c}$, which was also unable to develop on this medium. By excluding either menadione or tryptophan, it was possible to test to what extent the mutation had involved menaquinone synthesis only or the synthesis of all aromatic compounds. The original strains, with the above-mentioned exception, grew in the absence of both substances.

\section{Extraction and determination of menaquinones}

(a) Chemicals. The chemicals used were of the highest purity obtainable commercially and were not further purified. Standard K2 (30) vitamin was a gift from Dr Isler, Hoffmann-LaRoche Ltd, Basle, Switzerland. The petroleum ether used throughout was b.p. 60 to $110^{\circ}$.

(b) Spectroscopy. The ultraviolet spectra were measured in a Unicam model SP 800 recording spectrophotometer.

(c) Extraction of naphthoquinones. Cultures grown for $48 \mathrm{~h}$. on nutrient agar were suspended in normal saline and washed twice by centrifugation. Where indicated, the nutrient agar was supplemented with I $\mu \mathrm{g}$. menadione $/ \mathrm{ml}$. or $300 \mu \mathrm{g}$. shikimic acid $/ \mathrm{ml}$. The wet cells ( 50 to $100 \mathrm{ml}$.) were successively extracted, first with two portions of caetone (I50 ml.) and then with anhydrous ethyl ether (I50 ml.). For each extraction $50 \mathrm{mg}$. of pyrogallol were added to the mixture, which was mechanically stirred while 
being heated under reflux in a water bath for $90 \mathrm{~min}$. The pooled extracts were concentrated under reduced pressure to approximately $50 \mathrm{ml}$. by heating in a water bath under a stream of nitrogen and then extracted with four portions of petroleum ether (100 ml.). This extract was concentrated under reduced pressure in a water bath under a stream of nitrogen and the residue dried to constant weight in vacuo over $\mathrm{P}_{2} \mathrm{O}_{5}$.

(d) Chromatography. For chromatographic analysis the dried residue was dissolved in petroleum ether to a final concentration of $30 \mathrm{mg} . / \mathrm{ml}$. Analytical thin-layer chromatography was carried out on Chrom AR ${ }^{\mathrm{r}}$ sheet 500 (Mallinckrodt Chemical Works Ltd, Montreal, Canada), using petroleum ether + chloroform ( $\mathrm{r}: 4, \mathrm{v} / \mathrm{v})$ as the developing solvent, and the chromatograms were examined under u.v. light $\left(253^{\circ} 7 \mathrm{~nm}\right.$.). Under these conditions K 2 (30) gave a dark grey spot with $R_{F}$ value of 0.9. Preparative thin-layer chromatography was carried out on Chrom $\mathrm{AR}^{r}$ sheet rooo using the same solvent as above. The area of the chromatogram containing the menaquinones was removed and eluted with ethyl ether. The other solution was concentrated, rechromatographed, and the adsorbent eluted as above. The ether extract was concentrated and the residue dried to constant weight in vacuo over $\mathrm{P}_{2} \mathrm{O}_{5}$. Hexane solutions were used for u.v. analysis.

\section{RESULTS AND DISCUSSION}

Selection by means of neomycin and testing for catalase production resulted in the isolation of a large number of catalase-positive dwarf colony mutants of Staphylococcus aureus. With three exceptions, only those mutants that proved comparatively stable (during subsequent passages) were used in further experiments. A total of I 2 catalasepositive colony mutants of $S$. aureus were included in the investigation; their origin and characteristics are shown in Table I. Testing for the presence of vitamin $\mathrm{K}_{2}$,

Table I. Origin and characters of the catalase-positive dwarf colony mutants of Staphylococcus aureus

\begin{tabular}{|c|c|c|c|c|}
\hline \multirow[b]{2}{*}{ Mutant } & \multicolumn{2}{|c|}{ 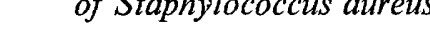 } & \multicolumn{2}{|c|}{ Stimulation by } \\
\hline & $\begin{array}{c}\text { Parental } \\
\text { strain no. }\end{array}$ & $\begin{array}{l}\text { Presence of } \\
\text { vitamin } K_{2}\end{array}$ & $\begin{array}{l}\text { Shikimic } \\
\text { acid }\end{array}$ & Menadione \\
\hline SHSL I & $3 \mathrm{c}$ & - & + & + \\
\hline SHSL 2 & II S & - & - & + \\
\hline SHSL 3 & NINA & - & - & + \\
\hline SHSL 4 & II s & - & - & + \\
\hline SHSL 5 & NINA & - & - & - \\
\hline SHSL 6 & 1363 & $*$ & + & + \\
\hline SHSL 7 & IIS & * & + & + \\
\hline SHSL 8 & $\mathrm{I} 363\left(\mathrm{Sm}^{\mathrm{r}}\right)$ & * & - & + \\
\hline SHSL I I & 1363 & - & - & + \\
\hline SHSL I3 & I $363\left(\mathrm{Sm}^{\mathrm{r}}\right)$ & - & - & + \\
\hline SHSL I4 & NINA & - & - & - \\
\hline SHSL 15 & NINA & - & - & - \\
\hline . & $3 c$ & + & . & . \\
\hline . & IIs & + & . & . \\
\hline . & NINA & + & . & . \\
\hline . & 1363 & $+\uparrow$ & . & . \\
\hline
\end{tabular}

* Presence of vitamin $\mathrm{K}_{2}$ not tested because of frequent reversion of the mutants.

$\uparrow$ The substance extracted has the same $R_{F}$ as standard vitamin K2 (thin-layer chromatography) but a different spectrum. 
in nine of these mutants revealed the absence of menaquinones (Table $\mathbf{I}$ ). In the other three mutants (SHSL6, SHSL 7, SHSL 8) such tests could not be carried out because of frequent reversion.

Supplementation of the medium with shikimic acid revealed the existence of three mutants (SHSL I, SHSL6, SHSL 7) that were stimulated by this metabolite. Since this indicates a mutation involving some stage prior to the synthesis of shikimic acid, we concluded that the mutants SHSL 6 and SHSL 7 , in which testing for vitamin K 2 could not be carried out, were also menaquinone-deficient mutants (meq-; cf. Săsărman et al. I968).

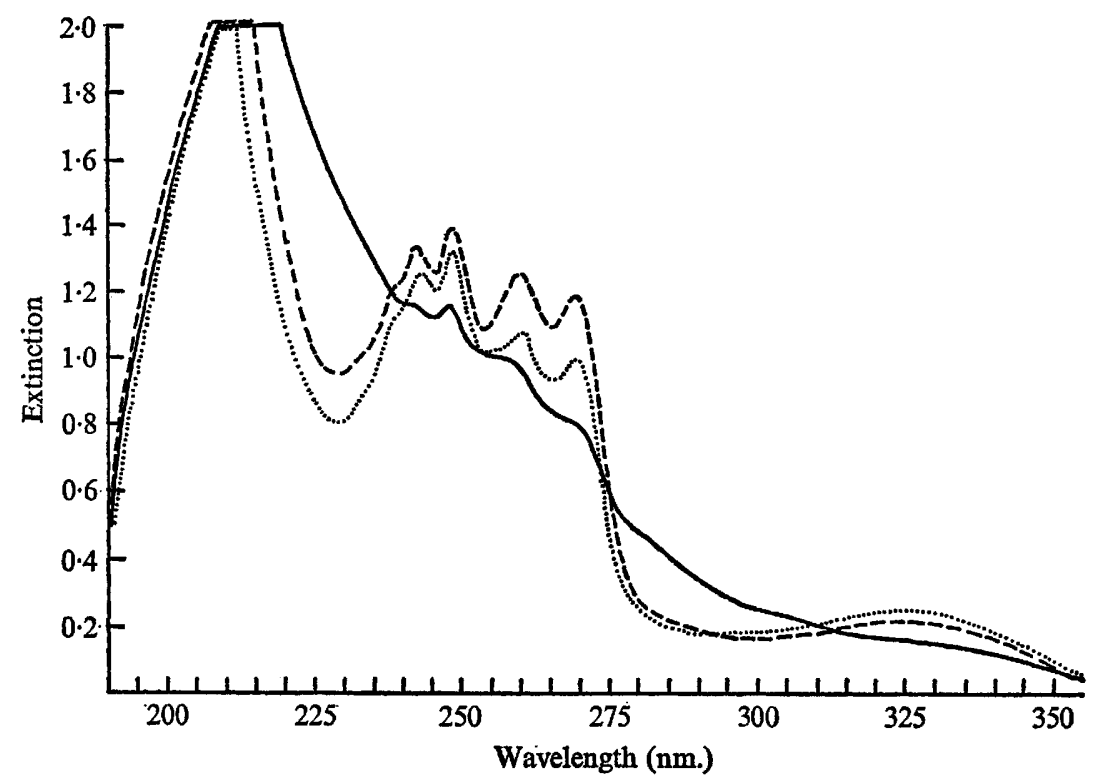

Fig. I. Spectra of menaquinones isolated by preparative thin-layer chromatography from extracts of Staphylococcus aureus. - - Strain SHSL I grown on nutrient agar +menadione, I $\mu \mathrm{g} . / \mathrm{ml}$.; - - , strain $3 \mathrm{c}$ grown on nutrient agar; ....., vitamin $\mathbf{K}_{2}(30)$ standard.

Examination of the influence of menadione on the growth of the meq- mutants revealed that most, including the mutant SHSL 8 in which testing for vitamin $\mathrm{K}_{2}$ was not feasible, were stimulated by this substance. Mutants grown in the presence of menadione form a compound with the $R_{F}$ of vitamin K 2 (30) (Săsărman et al. 1969; see also Hammond \& White, 1969), and this suggests that menadione is an intermediate in menaquinone synthesis as reported by Zenk \& Leistner (1968). However, examination of the substance synthesized by the mutants in the presence of menadione revealed a spectrum differing from that of vitamin $\mathrm{K}_{2}$ (Fig. I). In some instances this spectrum resembled that of a quinone extracted from the normal Staphylococcus aureus strain ${ }_{1363}$, which also has the $R_{F}$ value of standard vitamin K2 (30) but a different spectrum. It seems likely therefore that menadione is an analogue of some intermediate in menaquinones biosynthesis, probably of the first compound of the pathway possessing a naphthoquinone ring. Consequently, in menadione-stimulated mutants the mutation involves a stage prior to the biosynthesis of the naphthoquinone ring, whereas in mutants that are not stimulated by menadione some later step, related to the synthesis of the isoprenoid side chain of menaquinones, is probably affected. 
The nutrional requirements of $m e q^{-}$mutants and parental strains were compared to differentiate, among the menadione-stimulated mutants, those affected before from those affected after the separation of the aromatic metabolic paths. A requirement for tryptophan in meq- $^{-}$mutants indicated that the common part of the aromatic metabolic path had been affected. As was to be expected, the mutants stimulated by shikimic acid did not develop in the absence of tryptophan (Table 2). The mutant SHSL 8 was likewise unable to develop without tryptophan, so the lesion must also be within the common part of the metabolic path, at a stage subsequent to the synthesis of shikimic acid. The remaining mutants, which grew in the absence of tryptophan, were probably affected subsequent to the separation of the specific metabolic path in the synthesis of the naphthoquinone ring.

Table 2. Nutrient requirements of meq- mutants of Staphylococcus aureus

\begin{tabular}{|c|c|c|c|c|}
\hline \multirow[b]{2}{*}{ Mutant } & \multirow[b]{2}{*}{$\begin{array}{c}\text { Parental } \\
\text { strain no. }\end{array}$} & \multicolumn{3}{|c|}{ Growth on synthetic medium $C^{*}$} \\
\hline & & Complete & $\begin{array}{l}\text { Without } \\
\text { menadione }\end{array}$ & $\begin{array}{l}\text { Without } \\
\text { tryptophan }\end{array}$ \\
\hline SHSL I & $3 \mathrm{c}$ & $-\dagger$ & - & - \\
\hline SHSL 2 & II S & + & - & + \\
\hline SHSL 3 & NINA & + & - & + \\
\hline SHSL 4 & IIS & + & - & + \\
\hline SHSL 6 & I 363 & + & - & - \\
\hline SHSL 7 & IIs & + & - & - \\
\hline SHSL 8 & $1363\left(\mathrm{Sm}^{\mathrm{r}}\right)$ & + & - & - \\
\hline SHSL II & I 363 & + & - & + \\
\hline SHSL 13 & $1363\left(\mathrm{Sm}^{\mathrm{r}}\right)$ & + & - & + \\
\hline . & $3 \mathrm{c}$ & - & - & - \\
\hline . & I I S & + & + & + \\
\hline . & NINA & + & + & + \\
\hline . & 1363 & + & + & + \\
\hline
\end{tabular}

Table 3. Classification of the meq- mutants of Staphylococcus aureus

$\begin{array}{llccc}\text { Class } & \text { Mutant } & \begin{array}{c}\text { Stimulation } \\ \text { by } \\ \text { menadione }\end{array} & \begin{array}{c}\text { Ability to } \\ \text { synthesize } \\ \text { tryptophan }\end{array} & \begin{array}{c}\text { Stimulation } \\ \text { by shikimic } \\ \text { acid }\end{array} \\ \text { I } & \text { SHSL I } & + & \text { N.T. } & + \\ & \text { SHSL6 } & + & - & + \\ \text { II } & \text { SHSL 7 } & + & - & + \\ \text { III } & \text { SHSL8 } & + & - & - \\ & \text { SHSL 2 } & + & + & - \\ & \text { SHSL 3 } & + & + & - \\ & \text { SHSL 4 } & + & + & - \\ & \text { SHSL II } & + & + & - \\ \text { IV } & \text { SHSL 13 } & + & + & - \\ & \text { SHSL 5 } & - & - & - \\ & \text { SHSL 14 } & - & - & -\end{array}$


On the basis of the investigation reported here, the vitamin K-deficient mutants of Staphylococcus aureus selected by means of neomycin could be classified in four classes (Table 3). Only the mutants of the third and fourth classes are menaquinone-deficient in this strict sense of the term, the others being aromatic mutants affected at the level of the common metabolic path. The distribution of $m e q^{-}$mutants (Table 3 ) shows that the third class predominate; these mutants are of particular value for the elucidation of the biosynthesis of the naphthoquinone ring.

The excellent technical assistance of Miss Suzanne Grondin, Mrs Adriana Fonta, Miss Diane Legault, Miss Henriette Miral, Miss Ileana Stuparu, Miss Nelie Johnson and Mrs Elizabeth Tyskiewicz is gratefully acknowledged.

Part of this investigation was supported by grants MT-332, M.A. 3827 and MT-338 of the Medical Research Council of Canada.

\section{REFERENCES}

Bishop, D. H. L., Pandya, K. P. \& KING, H. K. (1962). Ubiquinone and vitamin K in bacteria. Biochemical Journal 83, 606-6I4.

Cox, G. B. \& Gibson, F. (1964). Biosynthesis of vitamin K and ubiquinone. Relation to the shikimic pathway in Escherichia coli. Biochimica et biophysica acta 93, 204-206.

Cox, G. B. \& Gibson, F. (1966). The role of shikimic acid in the biosynthesis of vitamin K 2. Biochemical Journal noo, I-6.

Gibson, F. \& Pittard, J. (1968). Pathways of biosynthesis of aromatic amino acids and vitamins and their control in micro-organisms. Bacteriological Reviews 32, 465-492.

HAMmond, R. K. \& WHITE, D. C. (1969). Formation of vitamin K 2 isoprenologues by Staphylococcus aureus. Journal of Bacteriology 100, 573-578.

Jeffries, L., Cawthorne, M. A., Harris, M., Diplock, A. T., Green, J. \& Price, S. A. (1967). Distribution of menaquinones in aerobic Micrococcaceae. Nature, London 215, 257-259.

Sǎsǎrman, A., Surdeanu, M., Portelance, V., Dobardzic, R. \& Sonea, S. (I969). Vitamin Kdeficient mutants in bacteria. Nature, London 224, 272.

Săsărman, A., Surdeanu, M., Szabados, J., Greceanu, V. \& Horodniceanu, T. (i968). Menaphthone-requiring mutants of Staphylococcus aureus. Revue Canadienne de Biologie 27, 333-339.

WEAVER, J. R. \& PATTEE, P. A. (1964). Inducible resistance to erythromycin in Staphylococcus aureus. Journal of Bacteriology 88, 574-580.

ZENK, M. H. \& LeISTNER, E. (1968). Biosynthesis of quinones. Lloydia 31, 275-292. 